American Journal of Applied Sciences 8 (10): 927-932, 2011

ISSN 1546-9239

(C) 2011 Science Publications

\title{
Lab-on-Chip Methodology in the Energy Industry: Wettability Patterns and Their Impact on Fluid Displacement in Oil Reservoir Models
}

\author{
${ }^{1,2}$ Marc H. Schneider and ${ }^{1}$ Patrick Tabeling \\ ${ }^{1}$ Microfluidique, MEMS and Nanostructures, UMR 7083 \\ Gulliver CNRS-ESPCI, Paris, France \\ ${ }^{2}$ Etudes et Production Schlumberger, 1 rue Henri Becquerel, 92140 Clamart, France
}

\begin{abstract}
Problem statement: We present an experimental study of multiphase transport in porous media with controlled wettability patterns based on lab-on-chip methodology. Approach: Fractional, or patterned, wettability is known to have an enormous impact in the petroleum industry on oil recovery and continuous efforts are being made to assess the role of such conditions. Results: Thus far, due to the absence of the technology required to produce micro fluidic networks modeling porous media (called "micromodels") with well-controlled wettability patterns, experimental results on this question have remained particularly elusive. We recently unlocked this bottleneck and can now selectively alter surface wettability within individual pores and thereby create precisely controlled wettability patterns within "micro models". Conclusion/Recommendations: The experiments we report here reveal the considerable impact of wettability patterning on the oil-water flow behavior (as compared with homogeneous wetting) and the consequence on the amount of liquid left after one phase has been swept through the network, information directly linked to the question of oil recovery.
\end{abstract}

Key words: Enhanced Oil Recovery (EOR), reservoir rock, environmental applications, porous media, multiphase transport, large pores, fluid displacement, reservoir wettability, prototyping techniques, microfluidic system

\section{INTRODUCTION}

Multiphase fluid transport in porous media dominates many industrial and environmental applications (Das and Hassanizadeh, 2005). Displacement processes in natural porous media, such as oil and natural gas reservoirs, play a crucial role during waterflooding, Enhanced Oil Recovery (EOR) or $\mathrm{CO}_{2}$ sequestration (Benetatos and Viberti, 2010; Verga and Rocca, 2010; Das and Hassanizadeh, 2005; Sahimi, 1993) which is of key importance to the petroleum and energy industries and displacement processes in aquifers and geothermal reservoirs are a major topic in soil science and hydrology (Sahimi, 1993; Hatiboglu and Babadagli, 2010). Examples for multiphase flow in synthetic porous matrices range from applications in classical chemistry (Sahimi, 1993) such as filtration of flow in packed columns (Abu-Ein, 2009) to gas-liquid transport in fuel cells (Bazylak et al., 2008; Litster et al., 2006) which are of major interest for energy applications (Berejnov et al., 2008).

A detailed understanding of multiphase flow processes at the microscopic scale is essential (Irwan et al., 2010) in order to describe their manifestation at the macroscopic level, in particular for EOR techniques employed in the oil industry (Musa et al., 2005). According to estimates, nearly 2 trillion bbl of conventional oil and another 5 trillion bbl of heavy oil, an amount corresponding to more than 200 years of the world's oil supply at current consumption rates, will remain in reservoirs worldwide after conventional recovery methods have been exhausted (Thomas, 2008). Oil companies currently exert extraordinary efforts to extract these residual reserves by injecting formulated fluids into the reservoirs through EOR techniques.

In this context, reservoir wettability is a crucial factor because it governs the flow behavior during immiscible fluid displacement within the porous reservoir rock (Maitland, 2000; Anderson, 1987). It is also a critical factor because most of the world's oil is locked in fractional-wet reservoirs; i.e., reservoir rock with wettability variations down to the pore level (Donaldson and Alam, 2008).

A variety of experimental and micro fabrication methods have been developed to study multiphase transport phenomena down to the pore level in a controlled environment. While earlier works relied on micromodels (i.e., porous rock models) made of glass

Corresponding Author: Marc H. Schneider, Microfluidique, MEMS and Nanostructures, UMR 7083 Gulliver CNRS-ESPCI, Paris, France 
Am. J. Applied Sci., 8 (10): 927-932, 2011

or transparent polymers made with classical fabrication methods (Blunt, 2001; Adler and Brenner, 1988; Guangyang et al., 2010) recent methods and approaches successfully harvest the benefits from rapid prototyping techniques and in particular micro models made from Polydimethylsiloxane (PDMS) (Berejnov et al., 2008; Cottin et al., 2010) based on soft lithography fabrication techniques (Xia and Whitesides, 1998). Such micromodels, which have played an instrumental role in the development of oil field technologies, (Sahimi, 1993) have been unable to reproduce any wettability pattern thus far that represents the realistic non-uniform state in oil reservoirs. This technological limitation has hampered efforts to analyze reservoir rock wettability and has jeopardized attempts to optimize or renew oil recovery techniques.

\section{MATERIAL AND METHODS}

In this communication, we take advantage of a recent technological breakthrough in wettability patterning, (Schneider et al., 2010) to produce micromodels with local wettability heterogeneities down to the pore level. We employ this new technique to selectively alter pore wettability by UV-initiated graft polymerization of Poly(Acrylic Acid) (PAA), as illustrated in Fig. 1a. A micrograph of an actual micromodel after selective surface treatment is shown in Fig. 1b. Hydrophilic surfaces were made visible by the stain toluidine blue, which adheres to the PAA graft but not to hydrophobic PDMS. In this particular example, all small pores (50 $\mu \mathrm{m}$ channels) were rendered hydrophilic while the large pores $(100 \mu \mathrm{m}$ channels) remained hydrophobic. This modification mimics very closely the wetting conditions of many oil reservoirs, where small pores and throats are believed to remain water-wet while large pores might be oil-wet (Kovscek et al., 1993; Salathiel, 1973).

Micromodels (i.e., microfluidic networks modeling porous media) were fabricated from PDMS according to a rapid prototyping technique based on soft lithography (Duffy et al., 1998; McDonald and Whitesides, 2002). In short, embossed microfluidic channel structures were created on a silicon wafer by a photolithographic patterning process of SU8 photoresist, serving as master. PDMS was cast by pouring a mix of pre-polymer and cross-linker (Sylgard 184 PDMS kit) on the mold and allowing it to reticulate for $2 \mathrm{~h}$ at $65^{\circ} \mathrm{C}$. After solidification, the PDMS cast was removed from the mold and bonded against a flat PDMS counterpart to form a micro fluidic system with closed channel structures. Permanent bonding was achieved by surface activation in oxygen plasma at $400 \mathrm{mT}$ orr for $30 \mathrm{~s}$ in a plasma cleaner. The devices were then annealed in an oven at $90^{\circ} \mathrm{C}$ for 2 days to reverse the plasma-induced surface changes and recover native PDMS hydrophobicity (Olah et al., 2005). Wettability patterns within the micromodels were achieved by UV-initiated graft polymerization of PAA (Schneider et al., 2010). In short, micromodels were primed with Photoinitiator Benzophenone (BP) by driving a solution of $10 \%$ (wt) $\mathrm{BP}$ in acetone through the device for $5 \mathrm{~min}$, allowing BP to diffuse into the PDMS matrix in vicinity of the channel walls (Schneider et al., 2011). After vacuum drying for $15 \mathrm{~min}$, the channels were loaded with a degassed solution of $20 \%$ (wt) acrylic acid (AA) in water and the system was exposed to UV light (365 $\mathrm{nm}$ ) through a photomask for 3-4 min at an intensity of $30 \mathrm{~mW} \mathrm{~cm} \mathrm{~cm}^{-2}$. After completion of graft photo77 polymerization the system was thoroughly rinsed with ethanol and water to remove all adsorbed material, leaving behind only the hydrophilic PAA coating covalently tethered to the PDMS surface in the desired regions.

The experiments involve displacing one fluid (water) with a non-miscible phase fluid (oil) for different wettability fractions, fw and analyzing the residual amount of displaced fluid, $S_{\mathrm{rw}}$, after the displacing fluid has percolated through the network and the evolution of the oil/water front has stopped (Fig. 2). Two different types of micromodels were used (Fig. 3), one with an ideal lattice isolating pure wettability effects and the other with distributed channel sizes mimicking an actual porous medium. Micromodel type I consisted of a regularly spaced lattice with 20,000 channels of uniform size $\left(80 \times 80 \times 220 \mu^{3}\right)$ with a node connectivity of 4 and no enlarged cavities at the nodes (Fig. 3b). The other micromodel type (II) was composed of 10,000 channels of variable size [(50-120) $\times 80 \times 300 \mu^{3}$ ] representing throats connected to 10,000 enlarged cavities $\left[(70-140)^{2} \times 80 \mu^{3}\right]$ at each node representing pores (Fig. 3c). Hydrophilic (waterwet) treatment was applied through UV exposure masks, which contained randomly placed square openings (500 $\times 500 \mu \mathrm{m}^{2}$ ) at sufficient numbers to create the desired wettability fraction, fw. Wettability was experimentally verified on samples for the hexadecane-water $(\mathrm{pH} 10)$ fluid system: In the presence of water, hexadecane is completely repelled from PAA grafted surfaces (oil contact angle $\theta$ oil $=180^{\circ}$ ) while hexadecane is strongly wetting native PDMS at $\theta$ oil $=30^{\circ}$.

Micro models were placed on a light table and imaged from above with a CCD camera. The resolution of the image sensor was sufficiently high to capture the entire network while providing good resolution $(10 \mu \mathrm{m}$ pixel resolution) in each individual channel to observe individual fluid interfaces. 


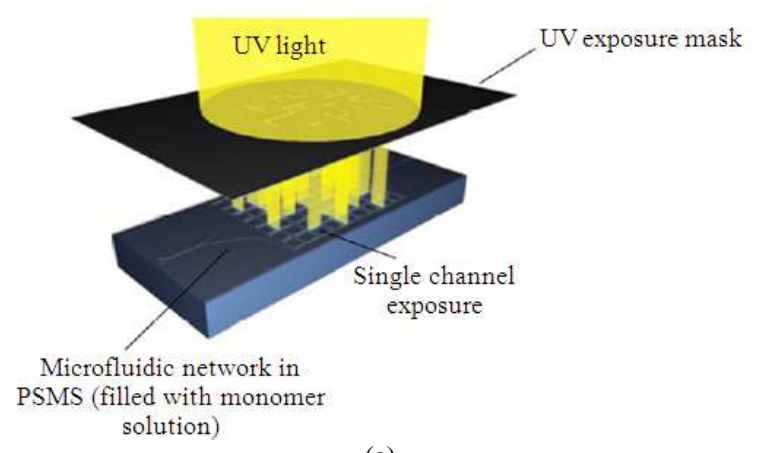

(a)

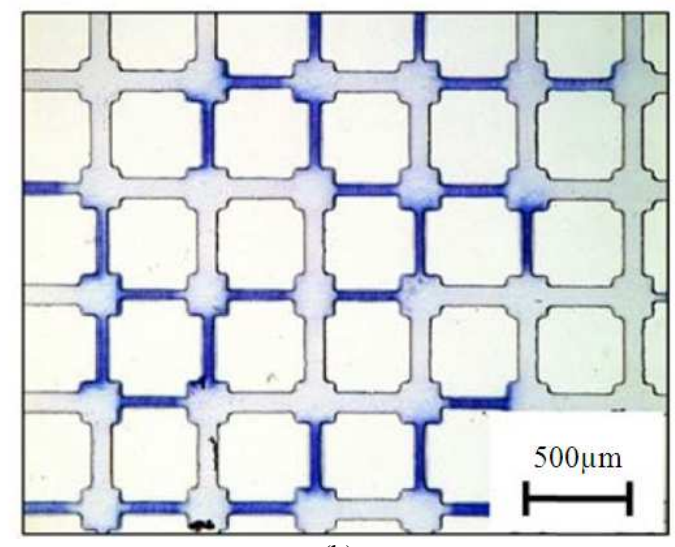

(b)

Fig. 1:Precision wettability patterning in PDMS micromodels by UV-initiated graft polymerization. (a) Schematic outline: Surface treatment is initiated in single pores (channels) within the PDMS chip by selective exposure to UV light. (b) Micrograph of a segment of an actual 158 PDMS micromodel. Channels with hydrophilic surface treatment are revealed by the stain toluidine blue

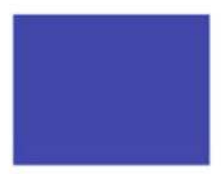

$\mathrm{t}=0$

Network filled with water

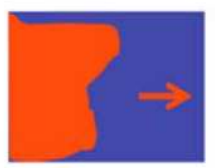

$t>0$

Oil is pushed at fixe flow-rate

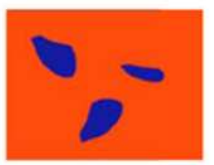

Large times Measure the quantity of water left
Fig. 2: Principle of the experiment: At $\mathrm{t}=0$, the micromodel, whose wettability has been patterned, is filled with water. At $t>0$, oil is injected and at large times (i.e., after percolation of oil through the network is achieved) the system reaches a steady state, in which residual water is left

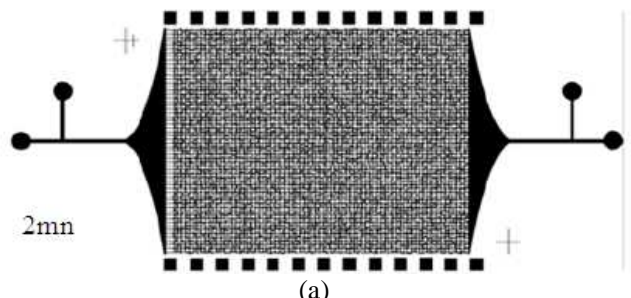

(a)

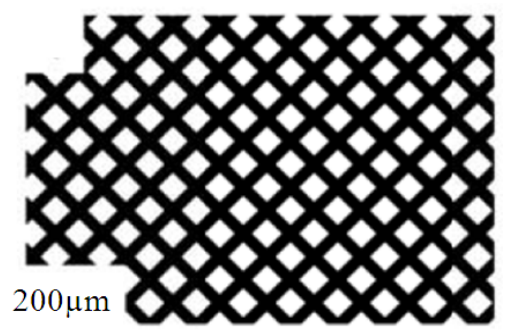

(b)

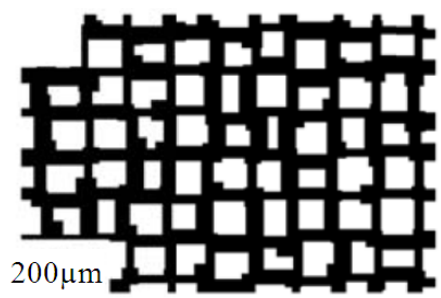

(c)

Fig. 3: Schematic outline of the micromodels used in this study. (a) General structure of the micromodel with fluid inlets and alignment structures. (b, c) Detailed structure of micromodel with (b) uniform channel size and (c) distributed channel size

Fluids were slowly injected by a high-precision syringe pump at a rate of $10 \mu \mathrm{L} \mathrm{min}$. Micromodels were initially filled with mildly alkaline water $(\mathrm{pH} 10)$ and then injected with hexadecane stained with the dye Oil Red, representing a low-viscosity mineral oil (3 cP). Hexadecane was predominantly invading the oil-wet native PDMS surfaces, while water was retained on the PAA grafted areas. An image sequence of each injection process was recorded at 3 frames $\mathrm{sec}^{-1}$ and each frame was automatically analyzed by a customdesigned image processing routine. The red oil is directly visible in the micrographs. To facilitate interpretation, water-filled channels are indicated in blue as an image overlay. A second image overlay indicates regions of different surface wettability: darkshaded areas indicate water-wet (treated) channels, while bright-shaded areas indicate oil-wet (untreated) 
Am. J. Applied Sci., 8 (10): 927-932, 2011

channels (see supplementary information [experiment.avi] for details).

\section{RESULTS}

Micromodels with uniform channel size $(\diamond)$ allow for the identification of pure wettability effects because they do not feature any preferential pathways imposed by geometry. Figure 4 shows a series of fluid displacement experiments in these micro models (type I) for various wettability fractions, $\mathrm{f}_{\mathrm{w}}$. As expected, the uniformly wetting case $\left(f_{w}=0 \%\right)$ is characterized by homogeneous invasion and complete displacement. However, close to the origin, minute changes in fw induce significant increases in residual fluid saturation $\mathrm{S}_{\mathrm{rw}}$ (Fig. 5a), more than only the water fraction trapped in the water-wet pores, as expressed by the ratio $S_{\mathrm{rw}} / f_{\mathrm{w}}$ (Fig. 5b). This phenomenon is also clearly visible in Fig. 4 for wettability fractions fw $<50 \%$, where water not only remains in water-wet regions (dark blue) but is also trapped in oil-wet patches (bright blue). In this first regime continuous pathways of oil-wet pores are characteristic, which allow oil to invade the network by circumventing water-wet pore clusters, a mechanism previously unreported in the literature. On the other end, at large $\mathrm{f}_{\mathrm{w}}$, another trend emerges in which Srw increases with decreasing fw (Fig. 4, $\mathrm{f}_{\mathrm{w}}>50 \%$ ). This trend is characterized by a combination of oil bursting through non-wetting zones (dark red) and spontaneous imbibition into isolated, discontinuous oil-wet structures (bright red), also absent from homogeneous systems. At $\mathrm{f}_{\mathrm{w}} \approx 0.5$, the two regimes are separated by a discontinuity resulting from the percolation threshold, where oil-wet and water-wet paths change from continuous to isolated and vice versa. Injection pressure profiles during constant flow-rate injection clearly confirm the different flow behaviors of the two regimes (Fig. 6). For $f_{w}>50 \%$, injection pressure almost instantly raises because the invading oil needs to be pushed through water-wet zones. On the other hand, for fw $<50 \%$, the continuously low injection pressures indicate oil invasion by spontaneous imbibitions along oil-wet pathways and pressures rise only when the exit face of the micro model is reached. Because more water is trapped and hence less oil is required to fill the systems for $\mathrm{f}_{\mathrm{w}}=40 \%$, injection pressure subsequently rises earlier as compared to the case for $\mathrm{f}_{\mathrm{w}}=0 \%$.

For systems with channel size distribution ( $\mathbf{\square})-\mathrm{a}$ situation that is closer to realistic porous media-the main features remain the same (Fig. 5), although the second regime is masked by geometry-induced percolation effects (Fig. 7).

Fig. 4:Fluid displacement experiments for micromodel type I with uniform channel size. Images show the final fluid distribution after each experiment at various wettability fractions, $f_{w}$. Oil-filled pores are shown in red and water-filled pores are shown in blue. Bright shade indicates oil-wet zones and dark shade indicates water-wet zones

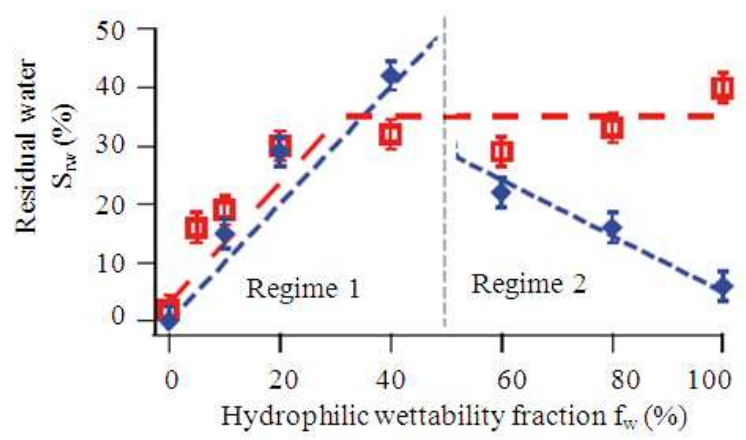

(a)

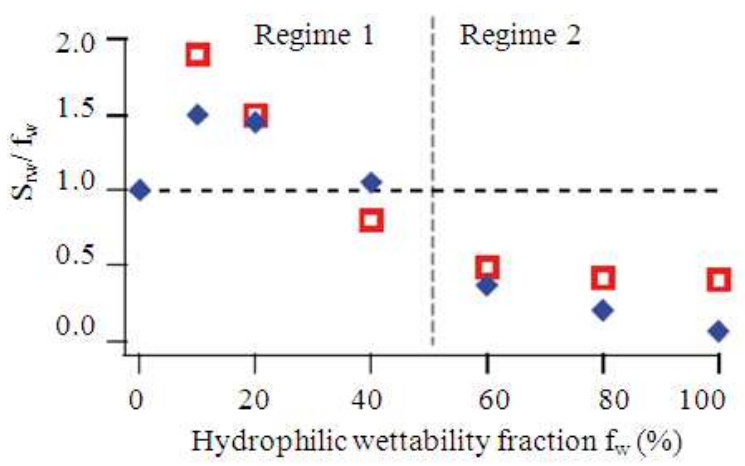

(b)

Fig. 5:Residual water saturation $\mathrm{S}_{\mathrm{rw}}$ (a) and aturation relative to hydrophilic zones (b) are shown for different wettability fractions, $\mathrm{f}_{\mathrm{w}}$. Experiments were performed $\mathrm{n}$ micromodels with uniform $(\diamond)$ and distributed ( $\boldsymbol{\square})$ channel sizes 


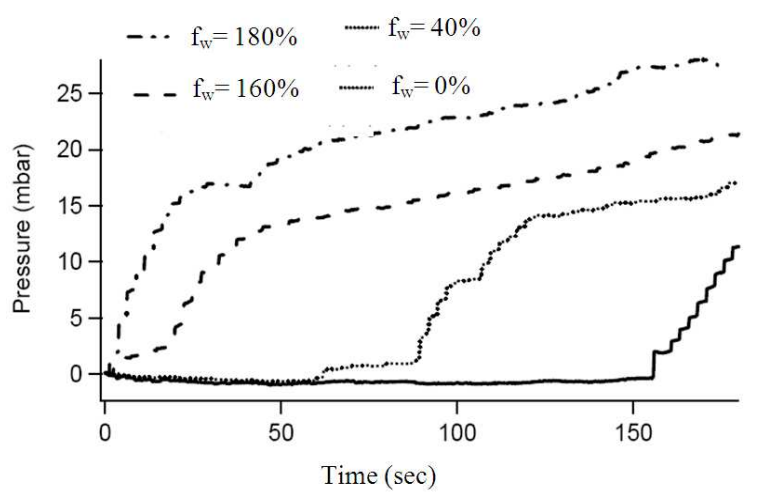

Fig. 6: Pressure evolution during fluid injection for micromodels with different wettability fractions. Pressure values represent measured injection pressures during constant flow-rate injection

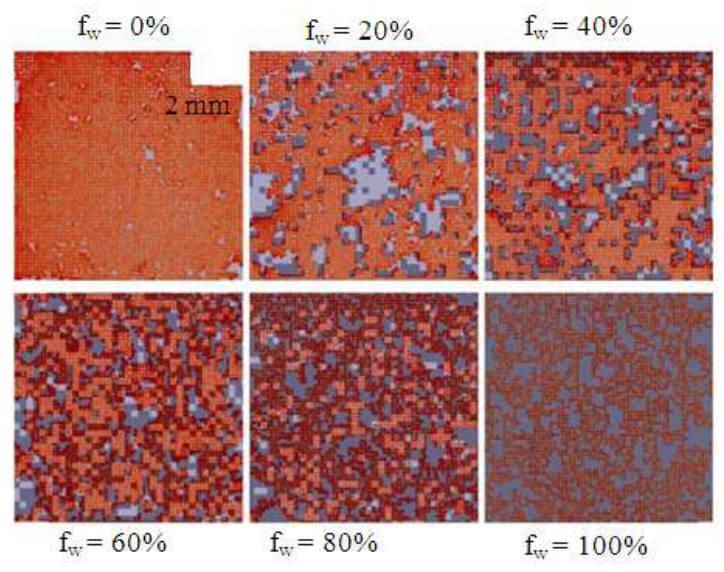

Fig. 7:Fluid displacement experiments for micromodel type II with distributed channel sizes. Each image shows the final fluid distribution after each experiment at a certain wettability fractions $f_{w}$. Oil-filled pores are shown in red and waterfilled pores are shown in blue. Bright shade indicates oil-wet zones and dark shade indicates water-wet zones

\section{DICUSSION AND CONCLUSION}

The experiments made on patterned micromodels uncover significant changes as the wettability fraction is varied and they reveal a pronounced sensitivity to the presence of small amounts of heterogeneities.

Systems with non-uniform wettability show an entirely different behavior than is presented in either the completely wetting $\left(\mathrm{f}_{\mathrm{w}}=0 \%\right)$ or non-wetting $\left(\mathrm{f}_{\mathrm{w}}=\right.$ $100 \%$ ) case. The differences revealed by our study are important: wettability heterogeneities raise the level of the residual fluid up to $40 \%$, which is a formidable quantity in the reservoir context. Importantly, the physical mechanisms underpinning this behavior do not depend on the dimensions of the system or its topology. We may conclude that the phenomena we highlight here should also occur in 3D reservoirs, despite the percolation threshold being shifted.

We have now reached a level of technology at which we can generate precise tools for detailed investigations of fractional wettability and its influence on fluid displacement in reservoir models. With most of the world's oil reserves trapped in mixed-wet reservoirs, our proposed tool may lead to a breakthrough in the development of improved EOR methods.

\section{REFERENCES}

Abu-Ein, S., 2009. Numerical and analytical study of exhaust gases flow in porous media with applications to diesel particulate filters. Am. J. Eng. Applied Sci., 2: 70-75. DOI: 10.3844/ajeassp.2009.70.75

Adler, P.M. and H. Brenner, 1988. Multiphase flow in porous media. Annu. Rev. Fluid Mech., 20: 35-59. DOI: 10.1146/annurev.f1.20.010188.000343

Anderson, W.G., 1987. Wettability literature survey. V: The effects of wettability on relative permeability. J. Petrol. Technol., 39: 1453-1468.

Bazylak, A., V. Berejnov, B. Markicevic, D. Sinton and N. Djilali, 2008. Numerical and microfluidic pore networks: Towards designs for directed water transport in GDLs. Electrochim. Acta, 53: 76307637. DOI: $10.1016 /$ j.electacta.2008.03.078

Benetatos, C. and D. Viberti, 2010. Fully integrated hydrocarbon reservoir studies: Myth or reality? Am. J. Applied Sci., 7: 1477-1486. DOI: 10.3844/ajassp.2010.1477.1486

Berejnov, V., N. Djilali and D. Sinton, 2008. Lab-onchip methodologies for the study of transport in porous media: Energy applications. Lab Chip, 8: 689-693. DOI: 10.1039/B802373P

Blunt, M.J., 2001. Flow in porous media-pore-network models and multiphase flow. Curr. Opin. Colloid In., 6: 197-207. DOI: 10.1016/S13590294(01)00084-X

Cottin, C., H. Bodiguel and A. Colin, 2010. Drainage in two-dimensional porous media: From capillary fingering to viscous flow. Phys. Rev. E., 82: 046315. PMID: 21230398

Das, D.B. and S.M. Hassanizadeh, 2005. Perface on upscaling multiphase flow in porous media: From pore to core and beyond. Transport Porous Media, 58: 1-3. DOI: $10.1007 / \mathrm{s} 11242-004-5463-7$ 
Donaldson, E.C. and W. Alam, 2008. Wettability. 1st Edn., Gulf Publishing Company, Houston, Texas, ISBN: 1933762292, pp: 336.

Duffy, D.C., J.C. McDonald, O.J.A. Schueller and G.M. Whitesides, 1998. Rapid prototyping of microfluidic systems in poly(dimethylsiloxane). Anal. Chem., 70: 4974-4984. DOI: 10.1021/ac980656z

Guangyang, L., W. Hong, Y. Yang, Y. Jinyuan and Y. Zhuoqing et al., 2010. Research in the improvement of wettability of micro-structure in patterned electrodeposition. Am. J. Nanotechnol., 1: 23-31. DOI: 10.3844/ajnsp.2010.23.31

Hatiboglu, C.U. and T. Babadagli, 2010. Experimental and visual analysis of co- and counter-current spontaneous imbibition for different viscosity ratios, interfacial tensions, and wettabilities. J. Petrol. Sci. Eng., 70: 214-228. DOI: 10.1016/j.petrol.2009.11.013

Irwan, M.A.M., A.M. Fudhail, C.S.N. Azwadi and G. Masoud, 2010. Numerical investigation of incompressible fluid flow through porous media in a lid-driven square cavity. Am. J. Applied Sci., 7: 1341-1344. DOI: 10.3844/ajassp.2010.1341.1344

Kovscek, A.R., H. Wong and C.J. Radke, 1993. A porelevel scenario for the development of mixed wettability in oil reservoirs. Am. Inst. Chem. Eng. J., 39: 1072-1085. DOI:10.1002/aic.690390616

Litster, S., D. Sinton and N. Djilali, 2006. Ex situ visualization of liquid water transport in PEM fuel cell gas diffusion layers. J. Power Sources, 154: 95-105. DOI: 10.1016/j.jpowsour.2005.03.199

Maitland, G.C., 2000. Oil and gas production. Curr. Opin. Colloid Interface Sci., 5: 301-311. DOI: 10.1016/S1359-0294(00)00069-8

McDonald, J.C. and G.M. Whitesides, 2002. Poly(dimethylsiloxane) as a material for fabricating microfluidic devices. Acc. Chem. Res., 35: 491499. DOI: $10.1021 / \operatorname{ar} 010110 \mathrm{q}$
Musa, T.A., A.A.E. Ibrahin, G. ZhenLiang and F. Qi, 2005. Optimization of field development scheduling, east unity oil field, Sudan. Am. J. Environ. $\quad$ Sci., 1: 29-33. DOI: 10.3844/ajessp.2005.29.33

Olah, A., H. Hillborg and J.G. Vancso, 2005. Hydrophobic recovery of UV/ozone treated poly(dimethylsiloxane): Adhesion studies by contact mechanics and mechanism of surface modification. Applied Surf. Sci., 239: 410-423. DOI: 10.1016/j.apsusc.2004.06.005

Sahimi, M., 1993. Flow phenomena in rocks: from continuum models to fractals, percolation, cellular automata, and simulated annealing. Rev. Mod. Phys., 65: 1393-1534. DOI: 10.1103/RevModPhys.65.1393

Salathiel, R.A., 1973. Oil recovery by surface film drainage in mixed-wettability rocks. J. Petrol. Technol., 25: 1216-1224.

Schneider, M.H., H. Willaime, Y. Tran, F. Rezgui and P. Tabeling, 2010. Wettability patterning by UVinitiated graft polymerization of poly(acrylic acid) in closed microfluidic systems of complex geometry. Anal. Chem., 82: 8848-8855. DOI: 10.1021/ac101345m

Schneider, M.H., Y. Tran and P. Tabeling, 2011. Benzophenone absorption and diffusion in poly(dimethylsiloxane) and its role in graft photopolymerization for surface modification. Langmuir, 27: 1232-1240. DOI: 10.1021/la103345k

Thomas, S., 2008. Enhanced oil recovery - an overview. Oil Gas Sci. Technol., 63: 9-19. DOI: 10.2516/ogst:2007060

Verga, F. and V. Rocca, 2010. Green methodologies to test hydrocarbon reservoirs. Am. J. Environ. Sci., 6: 1-10. DOI: 10.3844/ajessp.2010.1.10

Xia, Y. and G.M. Whitesides, 1998. Soft Lithography. Annu. Rev. Mater. Sci., 28: 153-184. DOI: 10.1146/annurev.matsci.28.1.153 